\title{
EARLY OBSERVATIONS OF THE LEONIDS IN EAST ASIA
}

\author{
I. HASEGAWA \\ Otemae Junior College \\ Itami 664 \\ Japan
}

\section{Introduction}

The parent comet of the Leonids, 55P/Tempel-Tuttle, was recovered in 1997. An improved orbit for the interval 1366 to 1997 together with predictions before 1366 were calculated by Nakano (1997). These orbital elements are used to determine the longitude of the descending node of the cometary orbit so that this can be compared with the solar longitude of meteors found in historic records. A number of catalogues listing the appearances of meteors showers have already been published. Most notable of these are Imoto and Hasegawa (1958), Zhuang (1977), Mason (1995), Rada and Stephenson (1992), Kidger (1993) and Hasegawa (1996). Nearly fifty records of the Leonids from AD855 to the end of the 19th century are found in these catalogues.

\section{Early Observations of bright Leonid meteors}

Some Chinese records of bright meteors also give star names along the meteor trail so that the radiant point can be determined. Beside shower records, we found a number of Chinese record of bright Leonid meteors as shown in the Table. The first recorded appearance in China was in AD 81, though the difference in longitude is rather large. We can not obtain the radiant from the Japanese records. However, between October 13 and 21 in 1434 many bright meteors fell in the early morning, moving from the east or north to the south. These could be Leonids since comet $55 / \mathrm{P}$ passed its perihelion in 1433 on July 31 and meteors were also recorded in China at this time.

In November 1705, about fifty meteors were observed by a Japanese government astronomer and these could be Leonids. 
TABLE 1. Bright Leonid Meteors Recorded in China and in Japan

\begin{tabular}{lllllll}
\hline Location & No. & $\begin{array}{l}\text { Year } \\
\text { AD }\end{array}$ & Date & $\begin{array}{l}\text { Sol. Long. } \\
\text { Eq 2000 }\end{array}$ & Long-node & time diff \\
\hline China & 1 & 81 & Sept 17 & 199.5 & -6.6 & +0.4 \\
& & & & & & \\
China & 2 & 1010 & Oct 14 & 220.2 & -0.1 & +9.4 \\
China & 3 & 1024 & Oct 11 & 217.6 & -2.7 & -10.2 \\
China & 4 & 1034 & Oct 13 & 219.1 & -1.3 & -0.2 \\
China & 5 & 1034 & Oct 13 & 219.1 & -1.3 & -0.2 \\
China & 6 & 1037 & Oct 12 & 218.3 & -2.2 & +2.8 \\
China & 7 & 1055 & Oct 17 & 222.7 & +1.6 & -14.4 \\
China & 8 & 1077 & Oct 14 & 220.0 & -2.0 & +8.6 \\
China & 9 & 1096 & Oct 16 & 222.2 & +0.3 & -5.7 \\
China & 10 & 1403 & Oct 23 & 226.5 & -0.3 & +3.4 \\
China & 11 & 1420 & Oct 27 & 231.1 & +4.2 & -12.8 \\
China & 12 & 1427 & Oct 23 & 226.3 & -0.6 & -5.8 \\
China & 13 & 1430 & Oct 21 & 224.5 & -2.4 & -2.8 \\
China & 14 & 1433 & Oct 24 & 227.8 & +0.8 & +0.2 \\
China & 15 & 1461 & Oct 24 & 227.6 & +0.6 & -4.8 \\
& & & & & & \\
Japan & 1 & 1171 & Oct 18 & 222.9 & -0.2 & +3.9 \\
Japan & $2 \mathrm{a}$ & 1434 & Oct 12.8 & 215.8 & -11.2 & +1.2 \\
Japan & $2 \mathrm{~b}$ & 1434 & Oct 13.8 & 216.8 & -10.2 & +1.2 \\
Japan & $2 \mathrm{c}$ & 1434 & Oct 18.8 & 221.8 & -5.2 & +1.2 \\
Japan & $2 \mathrm{~d}$ & 1434 & Oct 20.8 & 223.8 & -3.2 & +1.2 \\
Japan & 3 & 1705 & Nov 12.6 & 234.1 & +3.1 & +6.1 \\
\hline
\end{tabular}

\section{References}

Dall'olomo, U. (1978) Meteors, Meteor Showers and Meteorites in the Middle Ages: From European Medieval Sources, Jour. Hist. Astron.,ix,123-134

Hasegawa, I. (1993) Historical Records of Meteor Showers, in Stohl, J. and Williams, I. Meteoroids and their Parent Bodies, Astron. Inst. Slovak. Acad. Sci, Bratislava

Hadsegawa, I. (1996) Q. J. R. Astr. Soc.,37, 75-78

Imoto, S. and Hasegawa, I. (1958) Historical Records of Meteor Showers in China, Korea, and Japan,Smithsinian Contrib. Astrophysics, 2 (6), $131-144$

Kidger, M. R. (1993) Some Comments on the Identification of Medieval Meteor Showers Recorded by the Arabs, $Q$. J. R. Astr. Soc.,34, 331-334

Mason, J. (1995) The Leonid Meteors and Comet 55P/Tempel-Tuttle,J. Brit. Astron. Assoc.,105, 219-235

Nakano, S. (1997) Private Communication

Rada, W. S. and Stephenson, F. R. (1992) A Catalogue of Meteor Showers in Medieval Arab Chronicles, Q. J. R. Astron. Soc.,33, 5-16

Zhuang, T. (1977) Chinese Astr., 1, 197-220 